\title{
Development of low-resistance grounding resistor Da-jiang $\mathrm{HE}^{1, \mathrm{a}^{*} \text {, Jing XIAO }}{ }^{1, \mathrm{~b}}$, Pei ZHANG ${ }^{1, \mathrm{c}}$, ,Hen-ling YANG ${ }^{1, \mathrm{~d}}$ \\ ${ }^{1}$ College of electrical and Information Engineering, Huaihua University, China

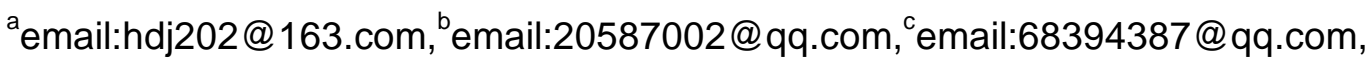 demail:65065325@qq.com
}

Keywords: Low Resistance, Grounding Resistor, Choice of Materials, Design Scheme, Simulation. Abstract. In this paper, the through-current experiments of various alloy materials in the analog ground fault state are carried out and the relevant force, heat, electric performance test and analysis have been accomplished too The part alloy materials which meet the requirements of the low resistance grounding resistor are selected, and on this basis the optimization design of resistance sheet shape, geometry size, space structure and overall arrangement is presented. The simulation results show that the selected alloy material and the structure design scheme satisfy the requirements of the low resistance grounding resistor. The research results for achieving the domestication of low- resistance grounding resistor is of great significance.

\section{Introduction}

In high voltage power distribution system, the choice of the grounding way of neutral point is a all-around technical matter, and the grounding way, such as ungrounded neutral point, arc-suppression coil grounding, direct grounding and through low-resistance grounding, have their own characteristics[1-3]. With constantly increase of load, the grid transmission system of overhead line is substituted by cable line gradually. Especially underground cable in the city and industrial estate increases rapidly, which brings the fact that the numerical value of capacitance current of the system rises substantially. In order to reduce inside over-voltage caused by single-phase short circuit, more and more neutral points ground in low-resistance1. In this way, the short circuit current is high(100A-2000A) and of short duration(10 seconds), and it will make the temperature of facility elevates fast (the temperature can reach $800^{\circ} \mathrm{C}$ ), which has a obvious impact on the performance of alloy material of grounding resistor, the resistor will be likely to be damaged because of distortion or melting .Grounding resistor material should have high resistivity to save materials, and low temperature coefficient, good stiffness and thermal properties to ensure the resistor operating steadily and safely in the grounding fault condition[4-9]. Since the grounding resistor is composed of multiple resistance units in series and parallel connection, the nonuniformity of temperature distribution in the process of through-current will lead to differences of force and thermal performance in different positions. How to effectively predict the temperature field distribution and the effect on the performances of materials in the condition of ground fault becomes the key of development of low resistance grounding resistor.

In this paper, on the basis of experimental study, the relevant problems of selecting materials and design scheme of low-resistance grounding resistor are discussed. The simulation results show that the selected alloy material and the structure design scheme satisfy the requirements of the low resistance grounding resistor.

\section{Selection of resistance materials}

Mechanical, thermal, and electric performance test of resistance materials. The resistance value of Grounding resistor is decided by the power grid voltage grade and the rated short circuit current, generally less than $10^{6}$. The grounding resistor is composed of resistance units of all shapes in series and parallel composition, when earth fault occurs, the temperature of resistor sheets rises rapidly, which has an obvious impact on the mechanical and thermal performance of electrothermal materials. So, more than 20 kinds of different type and specification electrothermal materials are tested 
regarding of mechanical, thermal, and electric performances. A large number of experimental data are obtained and analyzed, and the resistance material which meets the requirements of grounding resistor is acquired.

Selection of resistance materials. Experiments show that, generally, the resistivity of nickel-chromium and nickel-chromium-iron alloy is lower than iron-chromium-aluminum alloy. Considering the cost of materials, the decrease of volume and other factors, grounding resistor material can use iron-chromium- aluminum alloy4, and Chromium and aluminum are major elements to improve the resistivity. The influence of aluminum and chromium content on the resistivity can be seen from the figure 1 and figure 2 respectively. The resistivity increases with rising $\mathrm{Al}$ and $\mathrm{Cr}$ content, and the temperature coefficient of alloy material is associated with material composition, especially the content of nickel, chromium, aluminum and other major elements. The temperature coefficient of iron-chromium-aluminum alloy decreases with rising contents of aluminum and chromium. When aluminum content is low, the resistance temperature coefficient of iron-chromium -aluminum alloy is relatively big, and the resistivity increases obviously in the through- current process, and its mechanical and thermal stability becomes poor. The curve of iron- chromium-aluminum material resistance with temperature is shown as figure 3.

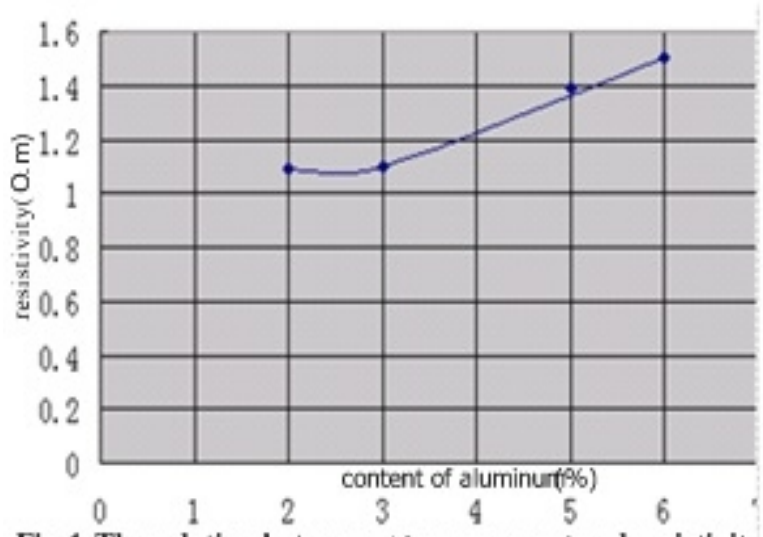

Fig 1 The relation between $\mathrm{Al}$ component and resistivity

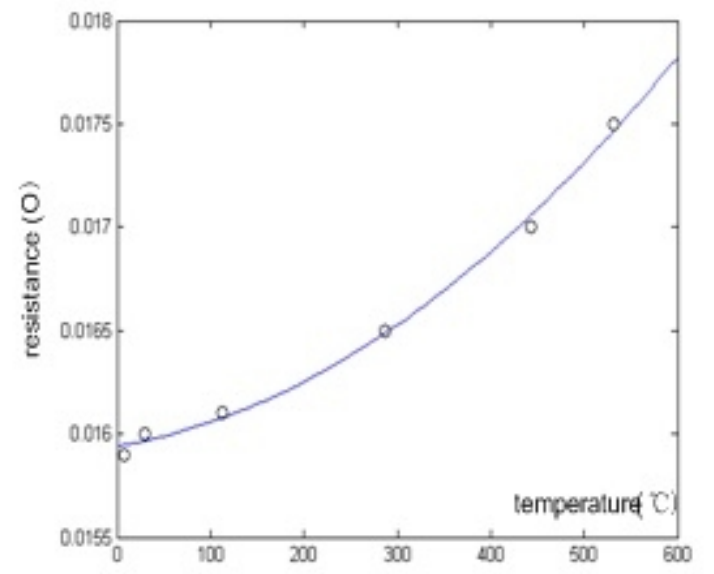

Fig 3 The variation curve of the resistance and the temperature.

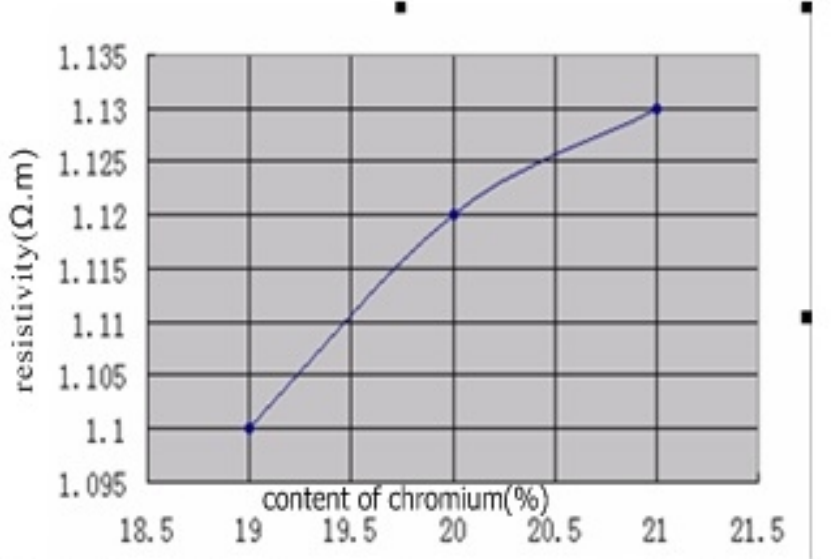

Fig.2The relation between $\mathrm{Cr}$ component and resistivity

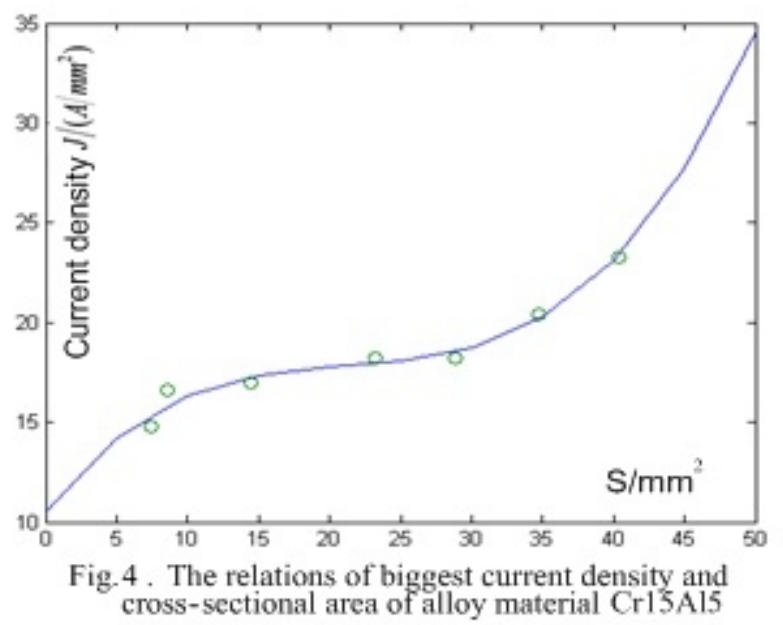

The maximum through-current density which all kinds of resistors can bear is related to its structure, shape and material properties. The maximum through-current density of same material increases with the growing cross-sectional area. The relationship curve between the maximum through-current density of an iron-chromium-aluminum alloy and the cross-sectional area is as shown in figure 4, and it is a nonlinear relationship. Considering the cost of materials and the decrease of volume, the maximum temperature rise needs to be improved as much as possible. The formula of temperature rise is as follows[7] (According to the adiabatic computing, regardless of other non-metallic materials absorption of heat). 


$$
S=\left(\frac{I^{2} \cdot \rho \cdot t}{c \cdot \gamma \cdot \Delta T}\right)^{1 / 2}=\left(\frac{I^{2} \cdot \rho_{0} \cdot t+I^{2} \cdot \rho_{0} \cdot \alpha \cdot \Delta T \cdot t}{c \cdot \gamma \cdot \Delta T}\right)^{1 / 2}
$$

In the formula (1), $\rho_{0}$ and $\alpha$ express resistivity of alloy material at $0^{\circ} \mathrm{C}$ and the temperature coefficient respectively, ${ }^{c}, \gamma$, and $S$ represents specific heat capacity, density and cross- sectional area, $\Delta T$ and $t$ indicates respectively the temperature rise and the current duration. As can be seen from the formula (1), the temperature rise is inversely proportional to the square of the cross-sectional area, the smaller the cross-sectional area, the higher the temperature rise. So, considering the cost of materials, the process of design should be based on the maximum service temperature. Of course, extremely high working temperature will affect operational stability and security of grounding resistor.

Generally, Nickel-chromium and nickel-chromium-iron alloy plasticity at room temperature is better to adapt to the complex cold bending deformation than iron-chromium-aluminum alloy. But the plasticity of iron-chromium-aluminum alloy material at room temperature declines with the increase of chromium-aluminum content, which means it, is not easy to manufacture and install electro thermal components. Especially, when iron-chromium-aluminum alloy is at low temperature $\left(0{ }^{\circ} \mathrm{C}\right)$ or near the high temperature $\left(950^{\circ} \mathrm{C}\right)$, its plasticity declines sharply and becomes embrittled, resulting the damage of the device4.After comprehensive consideration of all kinds of factors such as material resistivity, temperature coefficient, tensile strength, maximum through-current density, high temperature oxidation, and thermal expansion coefficient, two kinds of materials were selected for the grounding resistor, the relevant parameters are as shown in table 1.

Tab 1 The parameters of the selected resistance materials

\begin{tabular}{|c|c|c|c|c|c|}
\hline $\begin{array}{c}\text { Name of } \\
\text { material }\end{array}$ & $\begin{array}{c}\text { Resistivity } \\
(\mathrm{u} \Omega . \mathrm{m})\end{array}$ & $\begin{array}{c}\text { Temperature } \\
\text { coefficient } \\
\left(1 /{ }^{\circ} \mathrm{C}\right)\end{array}$ & $\begin{array}{c}\text { Tensile } \\
\text { strength } \\
(\mathrm{Mpa})\end{array}$ & $\begin{array}{c}\text { Density of } \\
\text { material } \\
\left(\mathrm{g} / \mathrm{cm}^{3}\right)\end{array}$ & $\begin{array}{c}\text { Specific } \\
\text { heat capacity } \\
\left(\mathrm{J} / \mathrm{g} .{ }^{\circ} \mathrm{C}\right)\end{array}$ \\
\hline $\begin{array}{c}\text { Material } \\
\mathrm{A}\end{array}$ & 1.35 & $1.14 \mathrm{e}-4$ & 690 & 7.34 & 0.48 \\
\hline $\begin{array}{c}\text { Material } \\
\mathrm{B}\end{array}$ & 1.12 & $5.4 \mathrm{e}-4$ & 720 & 7.323 & 0.486 \\
\hline
\end{tabular}

\section{Design of ground resistor}

Shape of the resistor sheets. In order to reduce the dimension of grounding resistors and increase the coefficient of heat transfer, the grounding resistor consists of a lattice of resistor sheets.

Calculation of single resistor sheet. The maximum adiabatic temperature rise is the highest temperature of this material which can be reached in certain through-current time, and it is an important reference to the selection of material dimension and through-current density. The calculation formula obtained by the formula (1) is shown in formula (2).

$$
\Delta T=\left(\frac{1}{A^{2}} \cdot \frac{C \cdot \gamma}{\rho_{0} t}-\alpha\right)^{-1}
$$

$\Delta T$ is the adiabatic temperature-rise, $\mathrm{A}$ is the maximum current density $(\mathrm{A} / \mathrm{mm} 2)$. Because the resistance temperature coefficient of electrothermal material $\alpha$ is relatively small, the formula can be simplified to

$$
\Delta T=A^{2} \rho_{0} t \cdot C^{-1} \gamma^{-1} .
$$

The calculation and design of the resistance unit is crucial in the design of resistor, and the selection of maximumcurrent density is the key to a resistance unit. From the experiment result, the cross-sectional area of the resistance sheet is relative to the through-current density and the 
larger the section area, the bigger the maximum current density. Meanwhile, the maximum adiabatic temperature-rise is directly proportional to the square of the through-current density, and the through-current density of resistor can be chosen according to the temperature rise. Due to the thermal dissipation, there is a large gap between the actual temperature rise and the adiabatic temperature rise. As a precondition of security and stability, considering the cost of material, the following 4 kinds of current levels are established for two types of material according to the experimental results, the maximum service temperature of resistance materials, design requirements and other factors. The maximum adiabatic temperature rise of resistors of each current level is shown in table 2. Tab 2 The maximum adiabatic temperature rise to each type of resistor

\begin{tabular}{|c|c|c|c|}
\hline $\begin{array}{l}\text { The name of } \\
\text { the material }\end{array}$ & $\begin{array}{l}\text { The highest } \\
\text { temperature } \\
\text { range }\left({ }^{\circ} \mathrm{C}\right)\end{array}$ & $\begin{array}{c}\text { Rated } \\
\text { current } \\
\text { ( A ) }\end{array}$ & $\begin{array}{l}\text { The highest } \\
\text { adiabatic } \\
\text { temperature rise } \\
\left({ }^{\circ} \mathrm{C}\right)\end{array}$ \\
\hline \multirow{4}{*}{ Material A } & \multirow{4}{*}{$1000-1100$} & 100 & 700 \\
\hline & & 400 & 750 \\
\hline & & 600 & 800 \\
\hline & & 1000 & 900 \\
\hline \multirow{4}{*}{ Material B } & \multirow{4}{*}{$1000-1100$} & 100 & 600 \\
\hline & & 400 & 650 \\
\hline & & 600 & 750 \\
\hline & & 1000 & 900 \\
\hline
\end{tabular}

According to the parameters in table 1 and table 2, the relevant parameters of single resistance sheet of various types of grounding resistor can be calculated by the adiabatic temperature rise, in the case of material A, assuming the rated fault current is $100 \mathrm{~A}$, the calculation of relevant parameters is as follows: when $\mathrm{I}=100 \mathrm{~A}, \Delta T=800^{\circ} \mathrm{C}$, the formula of through-current density derived from formula (3) is

$$
A=\sqrt{\frac{\Delta T C \gamma}{\rho_{0} t}}=14.45 \mathrm{~A} / \mathrm{mm} .
$$

The effective through-current sectional area of resistor $S=I / A=6.9 \mathrm{~mm}^{2}$, resistor width $\mathrm{a}=30 \mathrm{~mm}$, thickness $\mathrm{b}=\mathrm{S} / \mathrm{a}=0.23 \mathrm{~mm}$, which is roughly $0.25 \mathrm{~mm}$, and then calculate inversely the through-current density and adiabatic temperature rise by selected geometric dimension. The effective through-current length of each resistance sheet is $\mathrm{L} 1=665 \mathrm{~mm}$, then each sheet resistance value is $\mathrm{R} 1=0.1197 \Omega$, because the resistance value of each welding point on the resistor will be increased by $1.21 \%$ [6], and the variation of oxidation and temperature rise also leads to the increase of resistance, the total additional resistance is calculated by $1.5 \% * \mathrm{R} 1$, and then the resistance value of single resistor sheet is obtained. The relevant parameters of various types of resistor sheets can be calculated in the same method.

Tab.3 The arrangement parameters of entire resistor

\begin{tabular}{|c|c|c|l|l|l|c|}
\hline $\begin{array}{l}\text { The ame } \\
\text { of the } \\
\text { material }\end{array}$ & $\begin{array}{c}\text { Rated } \\
\text { current } \\
\text { ( A ) }\end{array}$ & $\begin{array}{c}\text { total } \\
\text { resistance } \\
(\Omega)\end{array}$ & $\begin{array}{l}\text { layer } \\
\text { number }\end{array}$ & $\begin{array}{l}\text { number } \\
\text { of each } \\
\text { layer }\end{array}$ & $\begin{array}{l}\text { distance } \\
\text { between } \\
\text { the slice } \\
(\mathrm{mm})\end{array}$ & $\begin{array}{l}\text { distance } \\
\text { between the } \\
\text { layers } \\
(\mathrm{mm})\end{array}$ \\
\hline $\begin{array}{c}\text { Material } \\
\text { A }\end{array}$ & 1000 & 5.774 & 5 & 76 & 10 & 448 \\
\hline $\begin{array}{c}\text { Material } \\
\text { B }\end{array}$ & 400 & 14.434 & 4 & 132 & 8.5 & 452 \\
\hline
\end{tabular}


Overall arrangement of resistor components. Assuming network voltage grade is $10 \mathrm{kV}$, the total resistance value of grounding resistor in different short-circuit currents can be obtained according to the relationship among voltage, resistance and the short-circuit current of grounding resistor. The total number of resistor sheets can be derived from the resistance value of single resistor sheet, those resistor sheets are arranged in even number layer with rational lamellar spacing and layer spacing. Take, for example, the short-circuit current 1000A of grounding resistor designed by material $\mathrm{A}$ and the short-circuit current 400A of grounding resistor designed by material B, the overall arrangement parameters of grounding resistor of corresponding specifications are shown in table 3.

\section{Simulation analysis of temperature field}

According to the design scheme, the temperature field distribution10-15 of grounding resistor of which rated fault current is 400A (through-current duration is 10 seconds) is simulated by analysis software ANSYS. Figure 5 is the temperature field distribution cloud chart of grounding resistor. Figure 6 shows the temperature-time curve of a node which is in the central position, the edge position or some other position during the through-current process. As can be seen from the figure 5, the highest temperature is $629.6^{\circ} \mathrm{C}$, and the overall temperature rise conforms to the objectives of design. The temperature in the center is approximately about 1.2times as much the temperature of edge in figure 6. Different temperature field distribution of grounding resistor can be obtained due to the change of the material and relevant parameters.

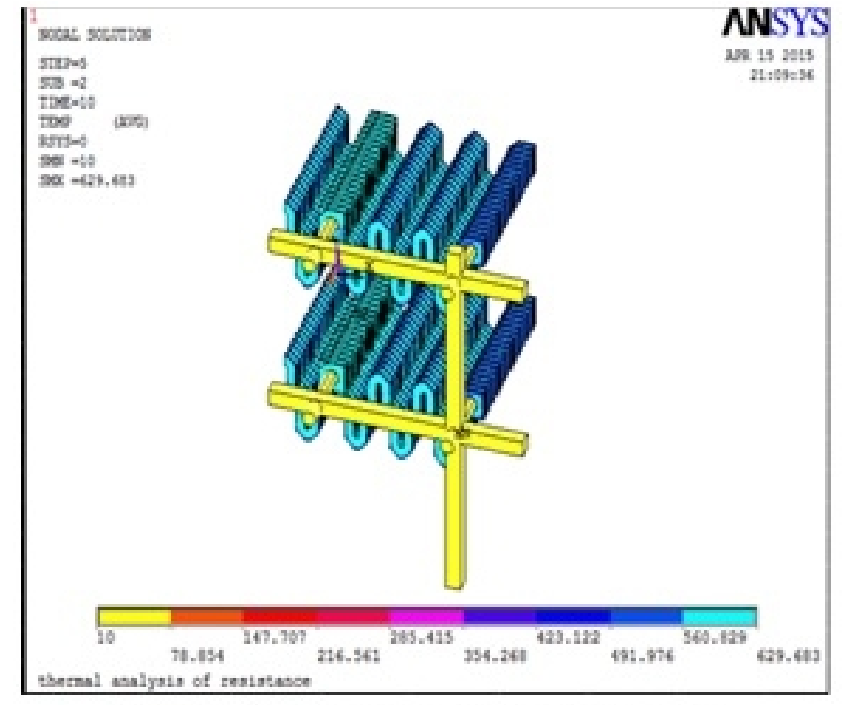

Fig5. Temperature distribution contour of the grounding resistor

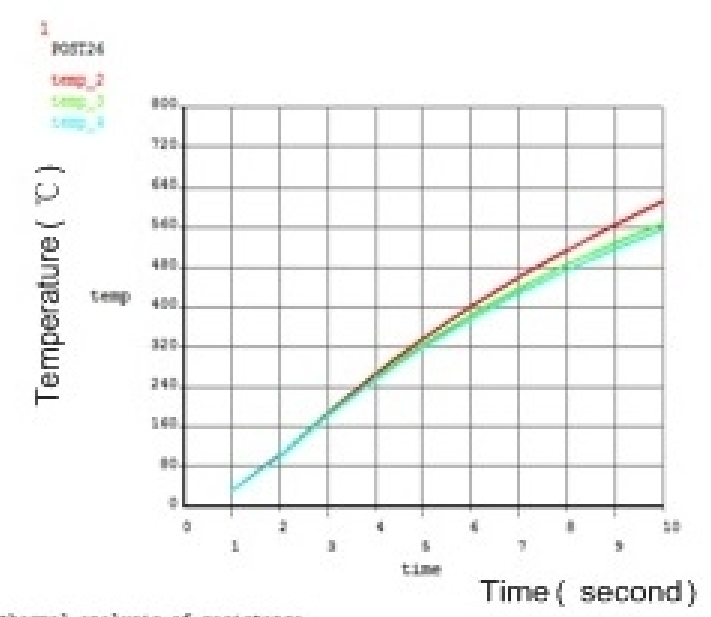

Fig.6. The temperature rise curve of differ position of the grounding resistor

\section{Summary}

Two materials are selected from the domestic electrothermal alloy materials. The experiment results show that the performance of those materials can basically satisfy the requirements of low resistance grounding resistor.

Selecting rational through-current density according to the development objects, mechanical and thermal performance of different materials is the key of grounding resistor design for different current levels.

Simulation results show that the design of the resistor is in accordance with the technical requirements of the low resistance grounding resistor. The research result is of great significance for promoting localization of low resistance grounding resistor. 


\section{Acknowledgment}

This project was financially supported by Scientific Research Foundation of Education Bureau of Hunan province (No.2011 FJ3143).

\section{References}

[1] Zhao Ran, Tan Weipu, Yang Yihan, "Analysis of neutral grounding operation modes for distribution network", Relay, vol. 35(4),pp. 22-26,2007.

[2] Liu Mingyan, "Selection of neutral grounding modes in power distribution network", Power System Technology, vol. 28(16),pp. 86-88,2004.

[3] Yao Huannian, Cao Meiyue, "On Neutral Grounding Modes of Cable Network", Power System Technology, vol. 27(2) ,pp. 84-89. 2003.

[4] Zhengdong Wang, Yuansheng Gong, "Electrothermal alloy", Beijing, Chemical industry press, 2006.

[5] Wenchao li, "The design, manufacture and use, maintenance of electric heater ", Beijing, Mechanical industry press, 1987.

[6] State bureau of technical supervision, "Neutral point grounding resistor of power distribution system (DL/T780-2001) ", Beijing, China standard publishing house, 2001.

[7] Chen Yu-shi,Jin Yi, Sun Chan, "Development of large-power loaded resistor", Journal of Yangtze River Scientific Research Institute, vol. 22 (1) ,pp. 60-62, 2005.

[8] Chen Linhui, Tian Huaizhang, Wang Shi, etc,"Research on temperature distribution and heat transfer of wrapped type heat exchanger", Journal of XiAn JiaoTong University, vol. 39(1) ,pp. 45-48, 2005.

[9] Bao dunwu, Li Caixia, Liu Wei, "Simulation research on the temperature field of medium plate heating-furnace", Metallurgy of Tianjin, vol. 2,pp. 3-6, 2003,

[10] Paulke J, Weichert H, Steinhaeuser P, “Thermal simulation of switchgear”, IEEE Transactions on Components and Packaging Technologies, vol. 25(3) ,pp. 6-11, 2002.

[11] Frei P U, Weichert H O, “Advanced thermal Simulation of a Circuit Breaker", Proceedings of the50th IEEE Holm

[12] Conference on Electrical Contacts and the 22nd International Conference on Electrical Contacts, pp. 104-110, 2004.

[13] Niu Chunping, Chen Degui, Liu Yingyi,et, "Temperature Field Simulation of AC Contactor and Analysis of Its Influence Factors", Transactions of China Electro technical society, vol. 22(5) ,pp. 71-77, 2007.

[14] Huang Linmin, Chen Degui, Zhang Jingshu, "Analysisof thermal field and transient thermal circuit of solenoid magnet by considering physical parameters as functions of temperatures", Transactions of China Electrotechnical Society, vol. 18(5) ,pp. 27-31, 2007.

[15] Wang Wenjing, Xie Jilong, Liu Zhiming,etc,“3-D Transient Temperature Field Analysis and Calculation for Brake Disc With Cyclic Symmetric Structure", Chinese Journal of Mechanical Engineering, vol. 38(12): ,pp. 131-134, 2002. 